\title{
Genetics and pathophysiology of mental retardation
}

\author{
Jamel Chelly*, Malik Khelfaoui, Fiona Francis, Beldjord Chérif and Thierry Bienvenu
}

Institut Cochin, Inserm - U567, CNRS - UMR 8104, Université Paris 5 René Descartes, Faculté de Médecine René Descartes, Paris, France

\begin{abstract}
Mental retardation (MR) is defined as an overall intelligence quotient lower than 70, associated with functional deficit in adaptive behavior, such as daily-living skills, social skills and communication. Affecting $1-3 \%$ of the population and resulting from extraordinary heterogeneous environmental, chromosomal and monogenic causes, MR represents one of the most difficult challenges faced today by clinician and geneticists. Detailed analysis of the Online Mendelian Inheritance in Man database and literature searches revealed more than a thousand entries for MR, and more than $\mathbf{2 9 0}$ genes involved in clinical phenotypes or syndromes, metabolic or neurological disorders characterized by MR. We estimate that many more MR genes remain to be identified. The purpose of this review is to provide an overview on the remarkable progress achieved over the last decade in delineating genetic causes of MR, and to highlight the emerging biological and cellular processes and pathways underlying pathogeneses of human cognitive disorders. European Journal of Human Genetics (2006) 14, 701-713. doi:10.1038/sj.ejhg.5201595
\end{abstract}

Keywords: mental retardation; XLMR; RhoGTPase pathways; neuronal morphogenesis and plasticity

\section{Definition}

Although controversies and debates over the definition and classification of mental retardation (MR) are still topical subjects, MR is defined as a disability characterized by significant limitations in intellectual functioning and in adaptive behavior, as expressed in conceptual, social and practical adaptive skills, that onset before the age of 18 years. ${ }^{1}$ Intellectual functioning and its severity is commonly based on the evaluation of Full Scale Intelligence Quotient (FSIQ), and MR, which could be regarded in many disorders as a symptom, is represented by an intelligence quotient (IQ) of 70 or less. On the basis of the IQ the most commonly used classification distinguishes two main categories: mild MR with an IQ between 50 and 70, and severe MR with an IQ below 50. Narrow definitions of MR restrict it to cases of non-progressive cognitive impairment detectable early after birth. None-

*Correspondence: Dr J Chelly, Institut Cochin, Faculté de Médecine Cochin Port Royal, 24, Rue du faubourg Saint Jacques 75014 Paris, France. Tel: + 331444124 10; Fax: 331444124 21;

E-mail: chelly@cochin.inserm.fr

Received 7 October 2005; revised 28 December 2005; accepted 29 December 2005 theless, numerous hereditary neurodegenerative and metabolic disorders characterized by progressive cognitive deterioration beginning some time after a period of normal development are often included among the disorders with MR. Rett's syndrome, a neurodevelopmental disorder characterized by cessation and regression of cognitive development that affect almost exclusively young females, is one of the examples that is difficult to reconcile with the conventional definition of MR, athough it is systematically classified as syndromic MR. In this review, we chose a broader, albeit less precise, definition that includes progressive disorders with onset of cognitive impairment in childhood.

Conventionally, genetic forms of MR are subdivided into two major categories - syndromic MR characterized by associated clinical, radiological, metabolic or biological features, and non-syndromic (or non-specific) MR forms in which cognitive impairment represents the only manifestation of the disease. Although this distinction remains very useful for clinical purposes, recent phenotypegenotype studies and detailed clinical follow-up of patients are indicating that the boundaries between syndromic and non-syndromic MR forms are vanishing, and some of the latter forms could be recognized as syndromic forms. ${ }^{2-6}$ 


\section{Prevalence and diagnosis}

In developed countries, MR represents the most frequent cause of severe handicap in children and one of the main reasons for referral in clinical genetic practices. Reported estimates are of $0.3-0.5 \%$ for moderate and severe MR $(\mathrm{IQ}<50)$ and of $1-3 \%$ when mild MR (IQ ranging from 50 to 70) is included (see review by Stevenson et $a l^{7}$ ), and genetic causes may account for $25-50 \%$ of severe MR cases. ${ }^{8}$ Causes of MR are extremely heterogeneous and can be environmental (malnutrition over pregnancy, environmental neurotoxicity, premature birth, perinatal brain ischemia, fetal alcohol syndrome, pre- or post-natal infections), chromosomal (aneuploidies, microdeletion syndrome), or monogenic (one finds 1177 Mendelian traits or genes in OMIM when searching for MR), but a precise cause is found only in about $50 \%$ of cases with moderate to severe MR, and in an even lower proportion for individuals with mild MR. In addition to conventional chromosomal aneuploidies, such as trisomy 21, that account for about $1.2 / 1000$ live births, compelling evidence are suggesting that subtelomeric rearrangements, as a group, may account for $5-7 \%$ of syndromic forms of MR. ${ }^{9}$ For monogenic causes, genes have mainly been found on the $\mathrm{X}$ chromosome than on any other comparable segment of the autosomes. This is partially related to the greater ease in pointing out $\mathrm{X}$-linked genetic disorders (including those characterized by MR) and in identifying the corresponding genes and mutations involved. Epidemiological studies repeatedly showed a sex bias, with $30-50 \%$ excess of males over females, and led to the assumption that much of the excess of male MR may be due to X-linked genes. ${ }^{7,10,11}$ If monogenic XLMR was to account for an excess of 30\% of mentally retarded males over females, one would expect that $20-25 \%$ of genetically based MR in males, including sporadic MR cases, are caused by XLMR genes (see also Supplementary information S2 in Ropers and $\mathrm{Hamel}^{5}$ ). However, recent molecular studies, ${ }^{12,13}$ in combination with clinical follow-up of a large cohort of patients, ${ }^{7}$ are suggesting that the proportion of monogenic XLMR in sporadic MR males would account at best for $8-10 \%$ of the genetic causes of MR. More generally, this new revision of estimates downwards and the recent progress in genetic counseling and prenatal diagnosis of specific MR conditions such as fragile $\mathrm{X}$ syndrome, as well as the lack of data concerning the prevalence of autosomal causes justify achievement of further epidemiological studies on MR. Moreover, as the frequency of premature birth has increased and control over pregnancy and perinatal periods of predisposing environmental and nutritional factors for brain damage have been improved, frequencies related to genetic versus nongenetic causes have perhaps evolved over the last decay. Such new epidemiological studies should allow better evaluation of genetic causes involved in cognitive impairment and recurrence risks in undiagnosed mental retardation.
Genetic causes and hypotheses for physiopathology On the basis of our current knowledge, MR resulting from constitutive or somatic mosaic deregulation of genetic information and programs might occur through (i) chromosomal rearrangements that result mainly into deleterious gene dosage effect, (ii) deregulation of the imprinting of specific genes or genome regions and (iii) dysfunction of single genes (monogenic causes of MR), which are individually required for development of cognitive functions (Table 1). MR resulting from these monogenic causes is either the only clinical manifestation of the disorders or a symptom of a clinical syndrome with or without detectable brain abnormalities. The section below should be regarded as an attempt to provide an updated view (but not an exhaustive list) of the genetic causes of MR, according to their involvement in the emerging molecular pathways and cellular processes thought to contribute to the physiopathological mechanisms underlying cognitive impairment.

\section{Chromosomal abnormalities, subtelomeric and interstitial rearrangements}

MR disorders resulting from aneuploidies such as trisomy 21, trisomy 13, trisomy 18 and partial chromosomal aneusomies such as $5 \mathrm{p}$ - have been the subject of regular extensive reviews, and will not be considered further in this review. However, in recent years, cryptic chromosomal

Table 1 Etiological classification of mental retardation

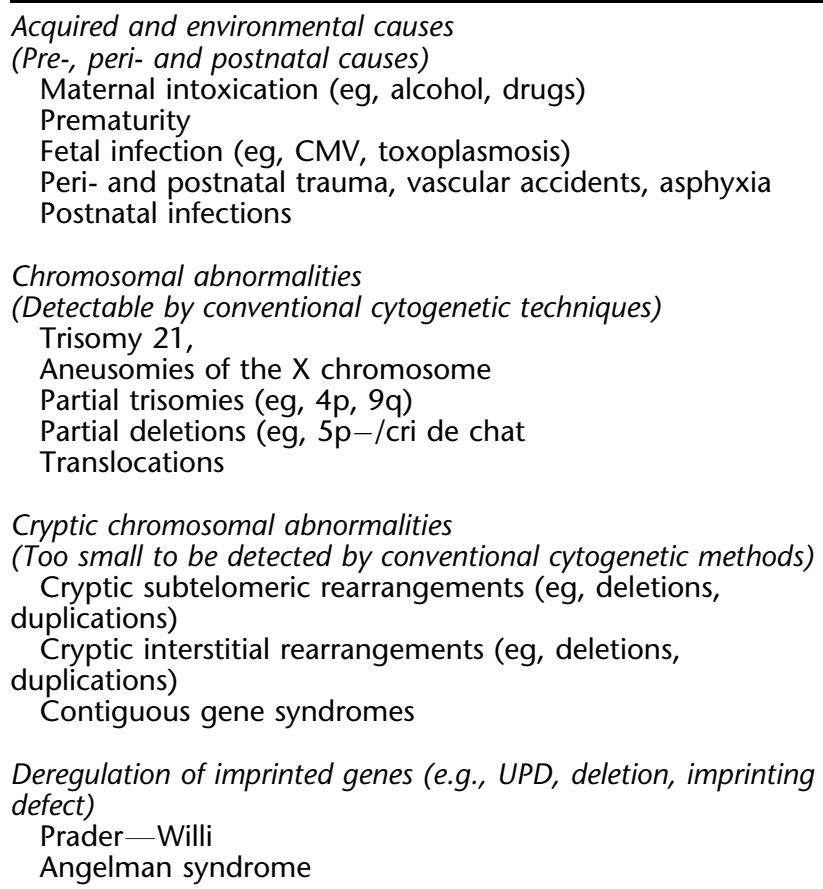

Chromosomal abnormalities

(Detectable by conventional cytogenetic techniques)

Trisomy 21,

Aneusomies of the $X$ chromosome

Partial trisomies (eg, 4p, 9q)

Partial deletions (eg, $5 p-/$ cri de chat

Translocations

Cryptic chromosomal abnormalities

(Too small to be detected by conventional cytogenetic methods) Cryptic subtelomeric rearrangements (eg, deletions, duplications)

Cryptic interstitial rearrangements (eg, deletions,

duplications)

Contiguous gene syndromes

Deregulation of imprinted genes (e.g., UPD, deletion, imprinting defect)

Prader-Willi

Angelman syndrome

Monogenic disorders (see Table 2). 
anomalies, particularly subtelomeric and interstitial rearrangements, for example, chromosomal deletions or duplications, too small $(<3-5 \mathrm{Mb})$ to be detected by conventional cytogenetic analysis have emerged as a significant cause of 'idiopathic $\mathrm{MR}^{\prime}{ }^{9,14,15}$ They usually involve several genes and cause contiguous gene syndromes. It is widely accepted that subtelomeric rearrangements, as a group, are responsible for $5-7 \%$ of all cases of $\mathrm{MR}$, intermediate in frequency between trisomy 21 and the fragile $\mathrm{X}$ syndrome. This high frequency stresses the need for the development of fast, efficient and reliable screening methods for subtelomeric rearrangements that can be used on a routine basis. A variety of methods have been successfully adapted for subtelomeric rearrangement screening, and at least seven different methods have been applied (reviewed in Rooms et $a l^{16}$ ). Multiprobe FISH and MLPA are the most widely used. Deletions of most, but not all, individual chromosome ends have been reported in patients with MR. ${ }^{9,17}$ Loss of specific chromosome ends may cause recognizable syndromes: Wolf-Hirschorn syndrome, caused by the deletion of the tip of chromosome $4 \mathrm{p}$; ATR-16 syndrome, caused by deletion of the tip of chromosome 16; or Miller-Dieker syndrome, caused by deletion of the tip of chromosome 17p. However, in many cases and because of the low number of patients with deletions, the definition of a specific phenotype associated with deletions of a particular chromosome end is sometimes not possible. Therefore, as the clinical phenotype of the patients provides few clues to orient the search for subtelomeric deletions, 'who to screen' within the population of MR patients remains a difficult issue. Guidelines have been proposed to facilitate pre-selection of patients among moderately-severely MR patients. ${ }^{18}$ However, in view of recent reports that showed significant rates of subtelomeric rearrangements among more mildly affected patients, ${ }^{19-21}$ screening of mild MR patients should not be excluded, athough further studies are required to confirm these initial observations. In addition to subtelomeric rearrangements, interstitial rearrangements have been implicated in a number of MR syndromes, including DiGorges (22q11 deletion), Williams-Beuren (7q11.2 deletion) and Smith-Magenis (17p11.2 deletion), and are diagnosed mainly by molecular cytogenetic approaches. Moreover, recent diagnostic studies using chromosomespecific, $^{22}$ or genomewide microarray-CGH (about 3500 clones at $1 \mathrm{Mb}$ resolution), ${ }^{23}$ have shown that interstitial chromosomal deletions or duplications may account for a significant proportion of unexplained MR. For instance, Van Esch et $a l^{22}$ showed that small duplications encompassing MECP2 region is a frequent cause of severe MR and progressive neurological symptoms in males. Alhough detection rate of these subtelomeric and interstitial abnormalities is largely dependent on the clinical inclusion criteria employed and the applied techniques, genomewide screening is likely to become a routine diagnostic approach in the field of MR. Another potential interesting consequence related to the detection of interstitial rearrangements is the definition of critical regions containing candidate genes involved in dominant autosomal MR. For instance, it has been shown that mutations in a new member of the chromodomain gene family cause CHARGE syndrome, ${ }^{24}$ and mutations of RAI1 (retinoic acid-induced ${ }^{1}$ gene), a PHD-containing protein, cause Smith-Maganis syndrome. ${ }^{25}$

\section{Deregulation of imprinted genes}

Genomic imprinting describes the preferential or exclusive expression of a gene from only one of the two parental alleles. The allele-specific expression of imprinted genes is based on allele-specific epigenetic modifications, such as DNA-cytosine methylation and histone acetylation and methylation. In the germ cells, these epigenetic modifications are erased, subsequently established newly in a parent-specific manner and maintained after fertilization. Imprinted genes are usually clustered in the genome, and clearly established imprinting effect has been reported for regions of chromosomes 7, 11, 14 and 15. Approximately, 80 transcriptional units have been identified as imprinted in human and mouse genomes ${ }^{26}$ (http://www.mgu.har. mrc.ac.uk/research/imprinting/). Deregulation of imprinted genes has been observed in numerous human diseases, including syndromes characterized by brain dysfunction and cognitive impairment. ${ }^{27,28}$ The most known of such diseases are probably the Angelman's syndrome (AS) and the Prader-Willi syndrome (PWS). AS is a worldwide disorder that occurs with a prevalence of about $1 / 12000 .^{29,30}$ AS patients suffer from severe speech deficit, severe MR and behavioral problems. The phenotype of PWS is characterized by neonatal hypotonia, hyperphagia, obesity, short stature, hypogonadism and MR of variable severity. ${ }^{27}$ Over the past 10 years, complementary studies demonstrated that AS and PWS are associated, in many cases, with microdeletions of the same genomic region corresponding to $1515 q 11.2-15 q 13$. Then it became evident that deletions of the paternally derived chromosome 15 caused PWS, and ones on the maternally derived chromosome 15 caused AS. The two syndromes are, however, caused by different genes, but they lie in an imprinted genomic region in close proximity to one another. Further studies showed that multiple molecular genetic mechanisms can lead to PWS and AS, but in PWS each mechanism results in a loss of expression of paternally imprinted genes, and in AS each mechanism leads to a loss of expression of maternally imprinted genes (reviewed in Nicholls and Knepper ${ }^{31}$ ).

\section{Monogenic causes involved in mental retardation disorders}

Because of the recent progress, genetics and classification of XLMR genes are the subject of regular reviews ${ }^{4-6}$ and 
updated lists can be found through the online resources: http://xlmr.interfree.it/home.htm and http://www.ggc. org/xlmr_update.htm. In a recent review, Inlow and Restifo $^{32}$ presented a status report on autosomal and $\mathrm{X}$-linked monogenic causes of MR through careful search for 'mental retardation' entries in the literature and in the Online Mendelian Inheritance in Man (OMIM) database (http://www.ncbi.nlm.nih.gov/entrez/). They identified more than 1237 entries for $\mathrm{MR}$ and recorded $282 \mathrm{MR}$ genes. A complete and accurate count of genes involved in MR disorders is perhaps beyond the scope of this review; however, given the number of OMIM entries for MR and the fact that in silico search for known genes is dependent of criteria such as clinical descriptions of disorders, definitions and terminology to design MR (learning disability, cognitive impairment, developmental delay...), it is reasonable to speculate that 282 genes represent a substantial underestimation of the correct number of MRrelated genes. Regardless of the scheme and rational used, it is difficult on the basis of our current poor understanding of molecular and biological functions of MR genes, as well as limited diagnostic possibilities, to propose a straightforward clinical or molecular classification of MR conditions. In this review, we propose to discuss first the apparent over-representation of MR genes on the $\mathrm{X}$ chromosome with respect to the autosomes, and attempt to provide a comprehensive overview of the monogenic causes that integrates clinical, genetic and functional considerations.

Chromosomal distribution of genes involved in mental retardation disorders Over the past few years, it is mainly the search for genes mutated in syndromic and nonsyndromic forms of X-linked MR that has been productive in recent years. No fewer than $60 \mathrm{X}$-linked genes involved in MR disorders have been identified. ${ }^{5,6}$ At first sight, the apparent excess of X-linked genes involved in MR disorders supports the hypothesis suggesting that the human $\mathrm{X}$ chromosome contains a disproportionately high density of genes influencing cognitive abilities. ${ }^{33-36}$ Using the human genome sequencing data and annotations, Skuse ${ }^{36}$ found that the $\mathrm{X}$ chromosome contains about 931 genes (ensembl version 26.31.1) that represent $3.37 \%$ of all genes, whereas 'X-linked mental retardation entries' corresponding to known genes and candidate loci represent 27\% (333) of the 1237 entries for 'mental retardation' recorded in OMIM database. The relative chromosomal distribution of MR genes has also been thoroughly analyzed by Inlow and Restifo. ${ }^{32}$ Approximately, out of 282 human MR genes, $16 \%$ reside on the $\mathrm{X}$ chromosome, whereas its content represent only 3.37$4 \%$ of all known and predicted genes (a four-fold overrepresentation). In line with these estimates is another OMIM-based analysis study reported by Zechner et al. ${ }^{37}$ The authors reported a 7.2-fold X-chromosome bias for MR genes, whereas genes causing common morphological phenotypes (polydactyly, cleft palate, facial dysplasia, skeletal dysplasia and growth retardation) have, on average, only a 2.4-fold X-chromosome bias. However, in view of some recent epidemiological and molecular data, this apparent biased distribution will probably not resist prospective studies that integrate recent estimates downwards of XLMR prevalence ${ }^{12,13}$ and contribution of submicroscopic rearrangements in MR conditions, as well as evaluation of the potential number of autosomal dominant and recessive MR genes, which are much more difficult to delineate because of the scarcity of affected families.

\section{Molecular and biological functions of genes involved in mental retardation Before summarizing our knowledge} concerning potential molecular and cellular processes underlying genetically based MR, a simplified classification that distinguishes $\mathrm{MR}$ with detectable cortical brain developmental abnormalities and MR with an apparent normal brain organization should be kept in mind. Indeed, in many cases, MR is part of a complex syndrome comprising developmental brain abnormalities such as microcephaly, lissencephaly, neuronal heterotopia, agenesis, polymicrogyria and schizencephaly, which result in a cerebral cortex that lacks the normal pattern of organization. MR in these cases is most likely to be a secondary symptom, and genes involved can be considered as factors required for normal development of the CNS. In contrast, MR conditions in which MR is associated with an apparent normal brain structure and architecture, subtle neuronal and/or glial cell functional, morphological or cell-cell interaction and connection abnormalities are likely to be the bases for MR. Accordingly, two major groups of genes could be distinguished: (i) genes involved in MR disorders with brain developmental abnormalities; (ii) genes involved in MR disorders with no specific brain abnormality, with an update concerning recessive autosomal MR genes. Alhough it has many weaknesses, this subdivision allows to highlight genes implicated in potential common genetic and functional pathways and provides bases and frameworks for understanding physiopathological mechanisms underlying MR (Table 2).

As we have recently discussed in a separate review monogenic causes and potential physiopathological mechanisms underlying MR disorders associated with brain malformation $^{38}$ (see also Table 2), here we focused on MR with no apparent developmental brain malformation and reviewed our current understanding of some of the primary defects involved, with insights from recent molecular biology advances and the study of mouse models. For the subgroup of MR disorders with no apparent brain malformation (irrespective of other potential distinguishing features), most of the known genes are X-linked, although the number of autosomal loci and genes involved in autosomal recessive nonsyndromic mental retardation 
Table 2 Monogenic causes of mental retardation

Function of encoded protein; subcellular localization*

\begin{tabular}{|c|c|c|}
\hline Gene & Locus & Disorder/phenotype \\
\hline \multicolumn{3}{|c|}{ Genes required for neurogenesis } \\
\hline Microcephalin & MCPH1/8p22-pter & Microcephaly vera \\
\hline CDK5RAP2 & $\mathrm{MCPH} 3 / \mathrm{q} 34$ & Microchephaly vera \\
\hline ASPM & $\mathrm{MCPH} 5 / 1 \mathrm{q} 31$ & Microchephaly vera \\
\hline CENPJ & $13 q 12.2$ & Microchephaly vera \\
\hline \multicolumn{3}{|c|}{ Genes required for neuronal migration } \\
\hline LIS1 & $17 p 13.3$ & $\begin{array}{l}\text { Miller Dieker syndrome: type } 1 \text { lissencephaly, } \\
\text { pachygyria, subcortical band heterotopia } \\
\text { (double cortex) }\end{array}$ \\
\hline $\mathrm{DCX} / \mathrm{Dbcn}$ & $\mathrm{Xq} 22.3$ & $\begin{array}{l}\text { Type } 1 \text { lissencephaly, pachygyria, subcortical } \\
\text { band heterotopia (double cortex) }\end{array}$ \\
\hline RELN & $7 q 22$ & Lissencephaly with cerebellar hypoplasia \\
\hline VLDLR & $9 p 24$ & Lissencephaly with cerebellar hypoplasia \\
\hline POMT1 & $9 q 34$ & $\begin{array}{l}\text { Walker-Warburg syndrome (also known as } \\
\text { HARD syndrome }{ }^{\star *} \text { ) }\end{array}$ \\
\hline РOMT2 & $14 q 24.3$ & Walker-Warburg syndrome \\
\hline POMGnT1 & $1 p 34$ & Muscle-eye-brain disease (MEB) \\
\hline Fukutin & $9 q 31$ & $\begin{array}{l}\text { Fukuyama congenital muscular dystrophy } \\
\text { (FCMD) with type } 2 \text { lissencephaly }\end{array}$ \\
\hline FLNA & $X q 28$ & $\begin{array}{l}\text { Bilateral periventricular nodular heterotopia } \\
\text { (BPNH) }\end{array}$ \\
\hline
\end{tabular}

Cell cycle control and DNA repair Mitotic spindle function in embryonic neuroblasts

Formation of mitotic spindle during mitosis and meiosis

Localization to the spindle poles of mitotic cells

Interacts with dynein and plays a role in several function, including nuclear migration and differentiation

Microtubule-associated protein (MAP)

Extracellular matrix (ECM) molecule, reelin pathway

Low-density lipoprotein receptor, reelin pathway

Protein o-mannosyltransferase 1

(glycosylation of alpha-dystroglycan)

Protein o-mannosyltransferase 2

(glycosylation of alpha-dystroglycan)

Protein o-mannose beta-1,2-nacetylglucosaminyltransferase Homology with glycoprotein-modifying enzymes (no biochemical activity has been reported).

Filamin-1 (actin crosslinking

phosphoprotein)

Genes required for cellular processes involved in neuronal and synaptic functions

FMR1 Xq27

Fragile $X$ syndrome (Facial anomalies with macro-orchidism)

$\begin{array}{lll}\text { FGD1 } & \text { Xp11.2 } & \begin{array}{l}\text { Aarskog-Scott syndrome (Facial, digital and } \\ \text { genital anomalies) } \\ \text { Nonsyndromic XLMR }\end{array} \\ \text { PAK3 } & \text { Xq21.3 } & \text { Nonsyndromic XLMR } \\ \text { ARHGEF6 } & \text { Xq26 } & \text { MR with cerebella and vermis hypoplasia }\end{array}$

$\begin{array}{lll}\text { TM4SF2 } & \text { Xq11 } & \begin{array}{l}\text { Nonsyndromic XLMR } \\ \text { NLGN4 }\end{array} \\ \text { DL22.3 } & \begin{array}{l}\text { Nonsyndromic XLMR, autism, Asperger } \\ \text { syndrome }\end{array} \\ \text { GDI1 } & \text { Xq13.1 } & \text { Nonsyndromic XLMR } \\ \text { IL1RAPL } & \text { Xq28 } & \text { Nonsyndromic XLMR } \\ \text { Xp22.1 } & \text { Nonsyndromic XLMR }\end{array}$

Transcription signaling cascade, remodeling and transcription factors

NF1 $17 q 11 \quad$ Neurofibromatosis type 1 (NF1); MR is present in $50 \%$ of NF1 cases
mRNA-binding protein, role in mRNA translation; potential regulation by RhoGTPase pathways; postsynaptic localization

RhoGEF protein (GTP exchange factor), activate Rac1 and Cdc42

P21-activated kinase 3; effector of Rac1 and Cdc42

RhoGEF protein, integrin-mediated activation of Rac1 and Cdc42 RhoGAP protein (negative control of RhoGTPases; stimulates GTPase activity of RhoA, Rac1 and Cdc42; pre- and post synaptic localization Member of the tetraspanin family, integrinmediated RhoGTPase pathway regulation Member of the neuroligin family, role in synapse formation and activity; post synaptic localization

Protein involved in postsynaptic density structures; postsynaptic localization Regulation of Rab4 and Rab5 activity, and of synaptic vesicle recycling; pre- and post synaptic localization

Potential involvement in exocytosis and ion channel activity

RasGAP function, involved in Ras/ERK/MAPK signaling transcription cascade; postsynaptic protein 
Table 2 (Continued)

\begin{tabular}{|c|c|c|c|}
\hline Gene & Locus & Disorder/phenotype & $\begin{array}{l}\text { Function of encoded protein; subcellular } \\
\text { localization* }\end{array}$ \\
\hline RSK2 & Xp22.2 & $\begin{array}{l}\text { Coffin-Lowry syndrome (facial and skeletal } \\
\text { anomalies) }\end{array}$ & $\begin{array}{l}\text { Serine-threonine protein kinase, } \\
\text { phosphorylates CREB, involved in Ras/ERK/ } \\
\text { MAPK signaling cascade, present in the } \\
\text { postsynaptic compartment }\end{array}$ \\
\hline CDKL5 & $\mathrm{Xp} 22.2$ & Rett-like syndrome with infantile spasms & $\begin{array}{l}\text { Serine-threonine kinase (STK9), interacts } \\
\text { with MECP2, potential implication in } \\
\text { chromatin remodeling }\end{array}$ \\
\hline CBP & $16 p 13.3$ & $\begin{array}{l}\text { Rubinstein-Taybi syndrome (mental } \\
\text { retardation, broad thumbs and toes, } \\
\text { dysmorphic face) }\end{array}$ & $\begin{array}{l}\text { CREB (CAMP response element-binding } \\
\text { protein } 1 \text { ) binding protein; chromatin- } \\
\text { remodeling factor involved in Ras/ERK/MAPK } \\
\text { signaling cascade }\end{array}$ \\
\hline EP300 & $22 q 13.1$ & Rubinstein-Taybi syndrome & $\begin{array}{l}\text { Transcriptional coactivator similar to CBP, } \\
\text { with potent histone acetyl transferase: } \\
\text { chromatin-remodeling factor }\end{array}$ \\
\hline XNP & Xq13 & $\begin{array}{l}\text { Large spectrum of phenotypes including } \\
\text { ATRX syndrome (microcephaly, facial } \\
\text { dysmorphic face, skeletal anomalies and } \\
\text { alpha-thalessemia) }\end{array}$ & $\begin{array}{l}\text { Homology with DNA helicases of the SNF2/ } \\
\text { SWI2 family, chromatin-remodeling factor, } \\
\text { regulation of gene expression }\end{array}$ \\
\hline
\end{tabular}

$\begin{array}{ll}\text { MECP2 } & \text { Xq28 } \\ \text { DNMT3B } & 20 q 11.2 \\ \text { ARX } & \text { Xp22.1 } \\ & \\ \text { JARID1C } & \text { Xp11.2 } \\ \text { FMR2 } & \\ \text { SOX3 } & \text { Xq28 } \\ \text { PHF8 } & \text { Xq27 } \\ \text { ZNF41 } & \text { Xp11.2 } \\ \text { GTF2I/ } & \text { Xp11.2 } \\ \text { GTF2RD1 } & 7 q 11.23 \\ \text { PHF6 } & \text { Xq26 }\end{array}$

Rett syndrome (female-specific syndrome) and other phenotypes including nonsyndromic MR

ICF syndrome: immune deficiency associated with centromeric instability, facial dysmorphy and MR Large spectrum of MR phenotypes: XLAG (Xlinked lissencephaly and abnormal genitalia); West syndrome, Partington syndrome; nonsyndromic MR

Spectrum of phenotypes: MR with microcephaly, short stature, epilepsy, facial anomalies and nonsyndromic MR Nonsyndromic MR Isolated GH deficiency, short stature and MR MR with cleft lip or palate

Nonsyndromic MR

Williams syndrome

Börjeson-Forssman-Lehmann syndrome (hypogonadism, obesity, facial anomalies, epilepsy)

Other genes involved in MR RPSS12 4q24

CRBN

$3 p 25$

CC2D1A

$19 \mathrm{p} 13$

FTSJ1

$\mathrm{Xq} 11.2$

PQBP1

Xq11.2

FACL4

Xq22.3

SLC6A8

Xq28

OCRL1

$\mathrm{Xq} 25$

AGTR2
Nonsyndromic ARMR

Nonsyndromic ARMR

Nonsyndromic ARMR

Nonsyndromic XLMR

Large spectrum of MR phenotypes including nonsyndromic MR

Nonsyndromic XLMR

Creatine deficiency syndrome (MR with epilepsy and dysmorphic features) and nonsyndromic MR

Lowe syndrome (MR, bilateral cataract and renal Fanconi syndrome)

Nonsyndromic XLMR
Methy-CpG-binding protein 2; chromatinremodeling factor, involved in a transcriptional silencer complex DNA methyltransferase $3 \mathrm{~B}$, involved in chromatin remodeling

Transcription factor of the aristaless homeoprotein-related proteins family

Transcription factor and chromatin remodeling

Potential transcription factor

SRY-BOX 3: transcription factor PHD zinc-finger protein, potential role in transcription

Potential transcription factor

Transcription factors, potential regulator of cFos and immediate-early gene expression Homeodomain-like transcription factor

Member of the trypsin-like serine protease family, enriched in the presynaptic compartment

ATP-dependent protease; regulation of mitochondrial energy metabolism Unknown function, protein contains C2 and DM14 domains

Role in tRNA modification and mRNA translation

Polyglutanime-binding protein, potentially involved in pre-mRNA splicing Fatty-acid synthase-CoA ligase 4; possible role in membrane synthesis and/or recycling Creatine transporter, role in homeostasis of creatine in the brain

Inositolpolyphosphate 5-phosphatase (central domain) and RHoGAP-like Cterminal domain

Angiotensin II receptor type 2, signaling pathway 
Table 2 (Continued)

\begin{tabular}{llll}
\hline Gene & Locus & Disorder/phenotype & $\begin{array}{l}\text { Function of encoded protein; subcellular } \\
\text { localization* }\end{array}$ \\
\hline SLC16A2 & $\mathrm{Xq13.2}$ & $\begin{array}{l}\text { Severe syndromic form MR with abnormal } \\
\text { levels of thyroid hormones } \\
\text { Snyder-Robinson syndrome (macrocephaly, }\end{array}$ & $\begin{array}{l}\text { Monocarbohydrate transporter, T3 } \\
\text { transporter }\end{array}$ \\
scoliosis, dysmorphic features) \\
SMS
\end{tabular}

The table does not represent an exhaustive list of genes involved in MR disorders. For additional genes, see the review by Inlow and Restifo, ${ }^{32}$ and online resources: http://xlmr.interfree.it/home.htm and http://www.ggc.org/xlmr_update.htm. *Subcellular localization is indicated mainly for protein shown to be present in the pre- and/or post-synaptic compartments; **HARD syndrome includes hydrocephalus (H), agyria (A), retinal dysplasia (RD), with or without encephalocele, often associated with congenital muscular dystrophies.

(NSMR) is progressively increasing (Table 2). Characterized MR-related genes encode diverse proteins that fall into distinct functional subclasses such as transcription and chromatin-remodeling factors, transmembrane proteins, microtubule- and actin-associated proteins, regulators and/ or effectors of RhoGTPase pathways. However, despite this apparent diversity, unifying biological networks and pathways underlying potential physiopathological mechanisms for MR are emerging and we propose to discuss in this review MR-related genes shown to be involved in neuronal connectivity and synapse structure and activity. We also propose to discuss the increasing evidence that link deregulation of transcription control and chromatin remodeling to cognitive impairment.

Synaptic structure and function and mental retardation The recent remarkable progress in the field of MR is suggesting that defects in synaptogenesis and synaptic activities as well as their plasticity, especially in postnatal stage during learning and acquisition of intellectual performances and emotional behavior, are perhaps crucial cellular processes that underlie cognitive impairment resulting from mutations in some MR-related genes. In accordance with this emerging hypothesis is the subcellular localization at the pre- and/or postsynaptic compartments of functional pools of proteins encoded by MR genes. With the exception of transcription factors and chromatin-remodeling proteins (see Discussion), this subcellular localization may hold true for most of the known MR-related proteins (Table 2), including FMRP, OPHN1, NLGN4, DLG3, RabGDI, Neurotrypsin and probably PAK3. For ILRAPL, the synaptic localization was suggested by its potential implication in regulation of exocytosis. ${ }^{39}$

A well-advanced research focus that illustrates the importance of the 'synapse' in the physiopathology of MR is FMRP protein, whose absence causes fragile $\mathrm{X}$ syndrome: the most common known monogenic cause of MR with no major apparent specific developmental brain anomaly. FMRP is an RNA-binding protein that could be detected in the nucleus, the soma as well as in the dendritic spines, where FMRP associates with polyribosomes and is upregulated in response to stimulation by metabotropic glutamate receptors (mGluRs). Morphological and/or functional abnormalities of synapses in the cerebral cortex, cerebellum and hippocampus have been shown and proposed to contribute in the cognitive deficit of fragile $\mathrm{X}$ patients (see review by Bagni et al ${ }^{40)}$. More recently, Koekkoek et al $^{41}$ showed that both global and Purkinje cellspecific knockout Fmr1 exhibit abnormal morphology of dendritic spines of Purkinje cells, correlating with synaptic dysfunction and cerebellar deficit at both the cellular and behavioral levels. These consequences on synapse morphology and activity are coherent with a local (at the synapse) function of FMRP as a regulator of activitydependent translation of mRNA-encoding proteins involved in actin/microtubule-dependent synapse growth, remodeling and function. ${ }^{40}$ Interestingly, using Drosophila model, Schenck et $a l^{42}$ showed that FMRP function is perhaps regulated through Rac1-, a member of the RhoGTPase subfamily, dependent signaling pathway. ${ }^{42,43}$

The importance of synaptic structure and function and their control through RhoGTPase signaling pathways in the physiopathology of $\mathrm{MR}$ is also supported by the compelling evidence including identification of MR genes such as OPHN1, PAK3, ARHGEF6 and FGD1, that encode regulators and/or effectors of RhoGTPases (Figure 1), and the recently demonstrated implication of OPHN1 and PAK3 in the regulation of dendritic spine morphology and/ or synaptic activity. ${ }^{4-46}$ It is worth noticing that OPHN1 was also found to interact with the postsynaptic adaptor protein Homer that links glutamate receptors (GluR-1) to multiple intracellular targets and influences spine morphogenesis and synaptic transmission. ${ }^{46}$

For PAK3 (p21-activated kinase), a member of PAK protein family that are activated by the two small RhoGTPases Rac and Cdc42 (cell division cycle ${ }^{42}$ ), the contribution in synapse formation and plasticity was clearly demonstrated by two groups. ${ }^{44,45}$ Using transient 


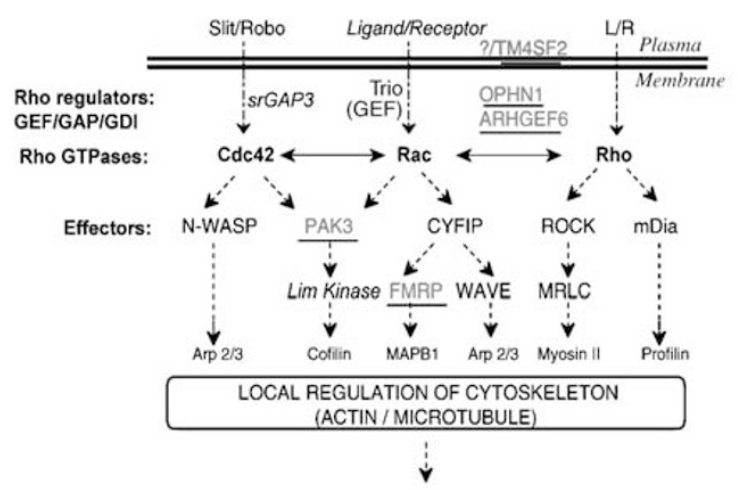

Neuronal and synaptic morphogenesis / function / plasticity

Figure 1 Simplified RhoGTPase signal transduction pathways and MR. Extracellular guidance cues (ligands) interact with growth cone, synaptic and membrane receptors and activate signaling cascades that involve RhoGTPases. Activated RhoGTPase pathways control actin/ microtubule cytoskeleton dynamics, which in turn regulate changes of growth cone, neuronal and synapse morphogenesis and activity. Interestingly, the dysfunction of these pathways through loss of function of PAK3 (p21-activating kinase), OPHN1 (RhoGAP), TM4SF2 (teraspanin), ARHGEF (RhoGEF) and FMRP (fragile $X$ mental retardation protein) (underlined proteins) leads to MR.

overexpression in hippocampal organotypic slice cultures, Boda $e t a l^{45}$ showed that PAK3 is localized at dendritic spines, and that PAK3 inactivation results in formation of abnormal dendritic spines and a reduced spontaneous synaptic activity and defective long-term potentiation (LTP). Meng et $a l^{44}$ generated a knockout mice model deficient for PAK3 and showed that this model exhibits significant abnormalities in synaptic plasticity, especially hippocampal late-phase LTP, and deficiencies in learning and memory. Surprisingly, in this knockout model, neither ex vivo cultures of hippocampal neuronal cells nor Golgi staining of fixed brain sections showed significant alteration in spine morphology, density or length. Although the mechanisms by which PAK3, an effector of Rac1 and Cdc42, produces these effects remain an intriguing question, it is well established that in response to both positive and negative external guidance cues, RhoGTPases are the key components of signaling pathways controlling the organization of the actin cytoskeleton, and in neuronal cells are known to regulate neurite outgrowth, growth cone morphology as well as growth cone guidance, synaptogenesis and neuronal networks connectivity. Establishment of these networks and their adaptation occur not only during brain development, but also in postnatal stages. Indeed, neuronal and synaptic remodeling and plasticity, including morphological changes of dendritic spines (structure localized at the postsynaptic sites of excitatory synapses), occur throughout life and are essential for the functioning of mature synapses as well as establishment of new ones. Although there is no demonstration that links defects of neuronal connectivity and MR, abnormalities of dendritic spines morphology and density have been observed, by Golgi studies on post-mortem brains, in several forms of MR disorders, including trisomy 21, fragile X and Rett's syndromes (reviewed in $^{47}$ ).

Potential roles in the regulation of synaptic activity have also been proposed for another subgroup of genes involved in MR conditions that encode for transmembrane proteins such as NLGN4 ${ }^{48,49}$ DLG3 $^{50}$ and IL1RAPL ${ }^{51}$ and for the soluble protein GDI1. ${ }^{52,53}$ At first sight, predicted primary functions of these proteins are diverse and different from those highlighted in the previous paragraph. However, it is interesting to mention, at least for the proteins that have been thoroughly analyzed, that these proteins have in common the subcellular localization at the pre- and/or postsynaptic compartments. NLGN4 gene has been found mutated in a wide spectrum of phenotype, ranging from mild MR without communication deficits to Asperger's syndrome with normal or supranormal intelligence. ${ }^{48,49}$ NLGN4 protein is a member of the neuroligin family of postsynaptic adhesion neuronal cell-surface molecules. It is particularly abundant in the postsynaptic membrane of exitatory and inhibitory synapses and can trigger postsynaptic differentiation as well as formation of functional presynaptic terminals in axons through interaction with its receptor $\beta$-neurexin. ${ }^{54,55}$ The importance of the regulation of synaptic activity in the pathogeny of MR is also reinforced by the implication in XLMR of another synaptic protein encoded by the DLG3 gene. ${ }^{50}$ DLG3 encodes the synapse-associated protein 102 (SAP102), a member of the membrane-associated guanylate kinase protein family. Mutations identified in DLG3 shown to be associated with MR are predicted to impair the ability of SAP102 to interact with NMDA receptors and/or other proteins involved in downstream NMDA receptor signaling pathways. ${ }^{50}$ For the two other XLMR-related genes, GDI1 ${ }^{52,53}$ and IL1RAPL, ${ }^{51}$ literature data are also suggesting their participation in the regulation of synaptic activity. In the mammalian brain, GDI $\alpha$ encoded by the GDI1 gene is the most abundant form of GDI in the CNS and was thought to be involved in the regulation of Rab proteins, which participate in synaptic vesicle recycling and fusion. ${ }^{56}$ RabGDI $\alpha$-deficient mice revealed a role for this protein in neurotransmitter release and synaptic activity in the hippocampus. ${ }^{57}$ More recently, D'Adamo et $a l^{58}$ have produced a mouse model deficient for Gdi1 and showed that the lack of Gdi1 has an effect on the distribution of Rab4 and Rab5 pools, which are Rab proteins involved in synaptic vesicle exocytosis and that GDI deficiency is associated with a defect in short-term memory. Implication in the regulation of synaptic activity was also proposed for IL1RAP, another X-linked gene involved in MR. Recent studies showed that IL1RAP interacts with NCS-1 (neuronal calcium sensor-1), and the functional relevance of this interaction was further strengthened by the regulatory effect of IL1RAPL on exocytosis known to be induced by NCS- $1 .{ }^{39}$ 
Altogether, these genetic data in combination with functional studies suggest that deregulation of subtle mechanisms orchestrating synaptic activity and plasticity could be regarded as one of the cellular bases that contributes to the pathogeny of a variety of autosomal and X-linked MR. In view of this emerging hypothesis, we are attempted to bring out the parallel between synaptic dysfunction thought to underlie cognitive impairment and synaptic biochemical variations, reported by Kandel et $a l,{ }^{59}$ associated with short- and long-term changes that reflect simple forms of memory storage. In their 'model', Kandel and colleagues described the process of memory storage and learning as a 'dialogue between genes and synapses' and proposed that short-term memory results from immediate synaptic biochemical changes (such as activation of CaMKII and increase in AMPA glutamate receptor activity), whereas long-term memory storage generally requires transcription and translation of new proteins that enhance the strength or number of active synapses. To bring further this hypothetical parallel, we can speculate that in MR conditions, inappropriate synaptic responses that follow sensory-motor stimuli could be relayed by a long-term synaptic defect through deregulation of signaling transcription cascades involved in the expression of factors that are crucial for synaptic morphogenesis, activity and plasticity. In favor of this view, which combines shortand long-term effects on synaptic activities, are the implication in MR, as primary defects, of transcription and remodeling factors (see below), and the fact that RhoGTPase-dependent MR genes may also be involved in the regulation of transcription signaling cascades regulated by RhoGTPase pathways. This transcriptional regulatory role in synaptic activity and plasticity also seems to be effective for PAK3, as knockout mice deficient for PAK3 exhibit a dramatic reduction of the phosphorylated active form of the transcription factor cAMP-response elementbinding protein.

Transcription control, chromatin remodeling and mental retardation MR disorders resulting from mutations in genes encoding transcription factors and cofactors, partners of signal transduction cascades, as well as chromatinremodeling proteins, represent a major group of monogenic causes of MR (Table 2). One of the most studied transcription-signaling cascades involved in cognitive disorders is the Ras-MAPK pathway (Figure 2). Among the Ras-MAPK pathway members shown to be involved in MR disorders are the proteins encoded by NF1, RSK2 and CBP genes (Figure 2). The product of NF1 has the capacity to regulate several intracellular processes, including the ERK-MAP kinase cascade, adenylyl cyclase and microtubule-binding activity ${ }^{60}$ In addition to neurofibromatosis, NF1 mutations result in MR in about $50 \%$ of patients. In an elegant study, Costa $e t a l^{61}$ inactivated in mice different isoforms of NF1 resulting from alternative splicing events,

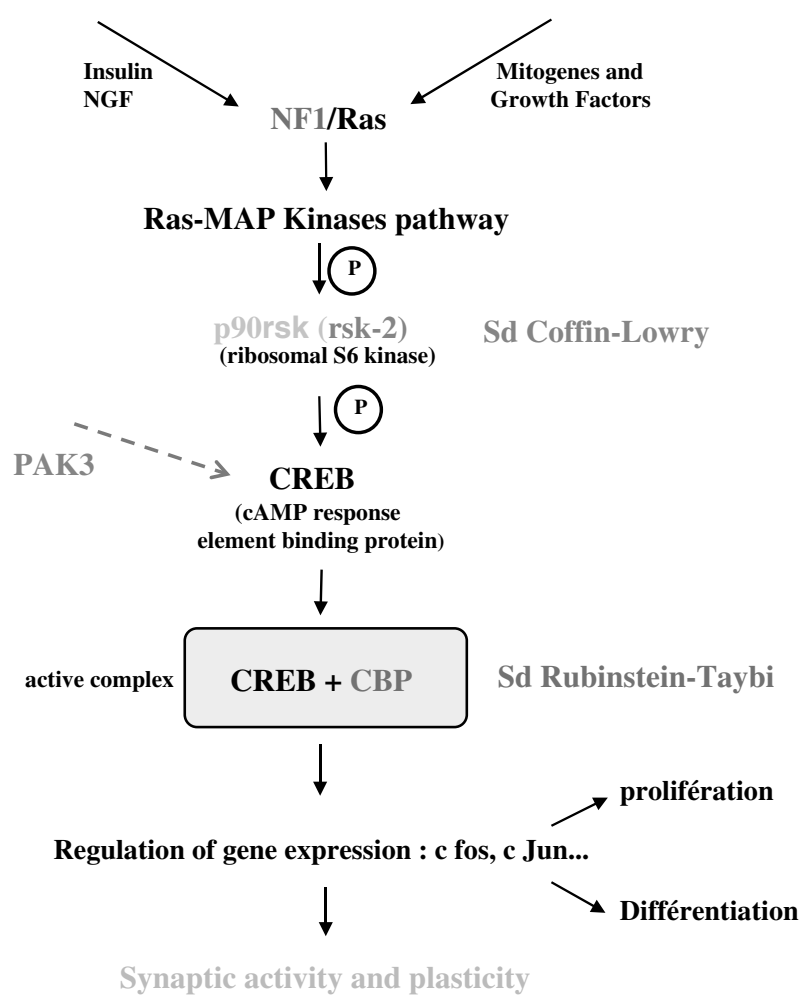

Figure 2 A schematic of the Ras/MAPK transcription-signaling cascade showing known genes/proteins (NF1, RKS2, CBP, PAK3) involved in MR disorders (NF1 and PAK3-related MR, Coffin-Lowry and Rubinstein-Taybi MR syndromes). This pathway was also shown in model organisms to be involved in learning and memory processes. These cognitive functions require gene transcription and translation of proteins. Newly synthesized proteins cause long-term changes of synapses, including dendritic spines development, morphogenesis and activity. NF1, neurofibromatosis type 1 oncogene; RAS, low molecular weight GTP-binding protein (G protein); MAPK, mitogen-activated protein kinase; CBP-, CREB-binding protein.

and identified the specific coding exon that contributes to the regulation of NF1-GAP domain and in the interaction with the NF1 target Ras as being critical for learning in mice and therefore may be involved in the pathogeny of cognitive deficit in humans. Downstream to NF1, Ras/ MAPK pathway activation requires CREB phosphorylation through kinases such as RSK2 (ribosomal protein S6 serine/ threonine kinase). Interestingly, RSK2 is the gene disrupted in Coffin-Lowry MR syndrome (CLS) ${ }^{62}$ and CREB phosphorylation was shown to be perturbed in fibroblasts from CLS patients. ${ }^{63,64}$ Moreover, another MR disorder associated with disruptions of the ERK/CREB pathway (Figure 2) is Rubinstein-Taybi syndrome (RTS). The gene involved in RTS was identified as CREB-binding protein (CBP), ${ }^{65}$ known to have intrinsic histone acetyltransferase activity. ${ }^{66}$ So, CBP seems to be important for chromatinremodeling events and gene regulation. Unlike CREB, which binds directly to a specific DNA sequence, CBP is a transcriptional coactivator that interacts with proteins 
such as phospho-CREB to regulate basal transcriptional complex activity.

An additional interesting example of MR-related gene encoding a protein implicated in chromatin remodeling is MECP2 (methyl-CpG-binding protein 2) gene. Mutations in MECP2 were found in the vast majority of Rett's syndrome patients. This is a female-specific syndrome characterized mainly by cessation and regression of development in early childhood that strikes many months after birth (about 12-18 months), following a period of apparently normal growth and development. Subsequent studies showed that both mutation type and patterns of Xchromosome inactivation $(\mathrm{XCI})$ are the bases for a surprisingly wide range of phenotypes, not only in females but also in males. ${ }^{67-70}$ Moreover, recent data showed that mutations in the cyclin-dependent protein kinase-like 5 (CDKL5/STK9) are responsible for neurodevelopmental disorder with clinical features that are reminiscent of Rett's syndrome. ${ }^{71,72}$ Given the clinical overlap resulting from mutation in MECP2 and CDKL5 genes, their involvement in a common genetic and pathogenic pathways has been suspected and further studies showed that spatio-temporal expression of Cdk15 overlaps with that of Mecp2 and that Mecp2 and Cdkl5 interact in vivo and in vitro. ${ }^{73}$

MeCP2 was first identified as a member of the methylCpG-binding domain (MBD) protein family. It binds to methylated $\mathrm{CpG}$ dimer pairs in DNA, and subsequent recruitment of transcriptional co-repressors such as $\operatorname{Sin} 3 \mathrm{~A}$ and histone deacetylases (HDAC) is thought to lead to chromatin condensation and repression of the expression of target genes. Comparative expression studies using knockout models allowed us to identify a limited number of differentially expressed genes, such as the brain-derived neurotrophic factor (BDNF) ${ }^{74-76}$ Interestingly, brain-specific inactivation of Mecp2 in postmitotic neurons of developing brain gave rise to a postnatal neurological Rettlike phenotype that is virtually indistinguishable from the mice in which constitutive inactivation of MeCP2 occurred in all tissues. ${ }^{77,78}$ These data indicate that brain function, rather than brain development per se, is sensitive to the absence of MeCP2. This finding is coherent with the growing body of evidence indicating that MeCP2 is important for maturation and maintenance of postmitotic neurons in rodent brains. ${ }^{79,80}$ Identification of target genes regulated by signaling transcription partners (NF1, RSK2 and CDKL5), chromatin-remodeling factors (MeCP2 and CBP) and transcription factors such as FMR2, SOX3 and ARX (Table 2) remains among the prerequisites to understand the biological and cellular processes underlying MR. However, despite this logical gap, much of the current advanced knowledge linking transcription regulators and development of cognition functions is the result of experimental work achieved over several decades that demonstrated a clear relation between some specific signaling transcription cascades - activity-dependent sy- naptic changes and learning and memory processes. ${ }^{59,81}$ Although definitions of neurobiological processes underlying MR are at an early stage, altogether these recent data indicate that specific transcription-signaling cascades and their downstream effects on the expression of target genes, some of which encode for synaptic proteins, are involved in the regulation of biological and cellular processes underlying in human MR physiopathological mechanisms and in animal models learning and memory processes.

\section{Conclusion}

The genetic heterogeneity that underlies cognitive impairment is unprecedented; however, in view of the current knowledge, a 'synapse-based' hypothesis for the pathogeny of several forms of MR could be proposed. Dysfunction of proteins encoded by genes involved in a large spectrum of cognitive deficits extending from mild MR with or without autistic and behavioral features to severe MR might lead, via deregulation of specific pathways and cellular processes, to defects in synaptic structure and/or function, and neuronal connectivity, thereby hampering the ability of the brain to process information. The resulting limited ability of the brain to process information would result in MR. In view of this hypothesis, it is tempting to speculate that in some forms of MR, deficient proteins are required in postnatal stages (during active learning periods) and the resulting deficits are likely to be subtle and to a certain extent may be prevented and/or improved if early postnatal diagnosis and appropriate therapeutic approaches are implemented. This assumption is based on the fact that behavioral and cognitive therapies can help mentally retarded patients reach their maximum potential. ${ }^{82,83}$ Also, MR owing to congenital hypothyroidism is now largely preventable through screening and hormone replacement. ${ }^{84}$ Other examples of efficient therapeutic approaches are dietary restrictions and supplements for inborn errors of metabolism such as phenylketonuria. ${ }^{85,86}$ Another example suggesting that cognitive deficits could, to a certain extent, be partially reversible is provided through the autosomal form of inborn errors of creatine biosynthesis that corresponds to guanidinoacetate methyltransferase (GAMT) deficiency. ${ }^{87}$ In this metabolic disorder with MR, cognitive impairment could be improved by arginine restriction and ornithine/creatine supplementation. ${ }^{88}$ Interestingly, the possibility of ameliorating learning capabilities by inhibiting histone deacetyltransferase was reported in animal models deficient for the $C b p$ chromatin remodeling factor. ${ }^{89}$ Moreover, McBride et $a l^{90}$ showed that a pharmacological approach using mGluR antagonists can rescue synaptic plasticity, courtship behavior and mushroom body defects in a Drosophila model of fragile X syndrome. Although therapeutic possibilities in human remain very rare, these examples emphasize, 
however, the necessity of establishing accurate diagnosis that could lead to preventive and therapeutic actions.

Finally, it should be stressed that genetic counseling and prenatal diagnosis related to mental handicap raise sensitive ethical issues, especially for the milder forms of $\mathrm{MR}$, or for carrier females who manifest subtle cognitive deficits. Assessing cognitive function is complex, and performances can be subject to profound social and environmental factors in the family and in schools. The level of expectation with respect to intellectual performances also depends on the family, and on the type of society to which an individual belongs. Great care should thus be exercised in the diagnostic and genetic counseling applications in this fascinating research domain.

\section{Acknowledgements}

We are grateful to all members of their laboratory and members of the European XLMR Consortium. Research studies performed by Chelly's group are supported by INSERM, CNRS and European Commission grants: QLG3-CT-2002-01810, Fondation pour la Recherche Médicale (FRM), Fondation Bettencourt-Schuler, Association Française du Syndrome de Rett, Fondation Jérôme Lejeune and Fédération pour la Recherche sur le Cerveau.

\section{References}

1 American Psychiatric Association: Task Force on DSM-IV: diagnostic and statistical manual of mental disorders: DSM-IV. Washington, DC: American pyschiatric association, 1994.

2 Frints SG, Froyen G, Marynen P, Fryns JP: X-linked mental retardation: vanishing boundaries between non-specific (MRX) and syndromic (MRXS) forms. Clin Genet 2002; 62: 423-432.

3 Chelly J: Breakthroughs in molecular and cellular mechanisms underlying X-linked mental retardation. Hum Mol Genet 1999; 8: $1833-1838$.

4 Chelly J, Mandel JL: Monogenic causes of X-linked mental retardation. Nat Rev Genet 2001; 2: 669-680.

5 Ropers HH, Hamel BC: X-linked mental retardation. Nat Rev Genet 2005; 6: 46-57.

6 Chiurazzi P, Tabolacci E, Neri G: X-linked mental retardation (XLMR): from clinical conditions to cloned genes. Crit Rev Clin Lab Sci 2004; 41: 117-158.

7 Stevenson RE, Schwartz CE, Schroer RJ: X-linked mental retardation. New York, Oxford: Oxford University Press, 2000.

8 McLaren J, Bryson SE: Review of recent epidemiological studies of mental retardation: prevalence, associated disorders, and etiology. Am J Ment Retard 1987; 92: 243-254.

9 Flint J, Knight S: The use of telomere probes to investigate submicroscopic rearrangements associated with mental retardation. Curr Opin Genet Dev 2003; 13: 310-316.

10 Herbst DS, Miller JR: Nonspecific X-linked mental retardation II: the frequency in British Columbia. Am J Med Genet 1980; 7: $461-469$

11 Fishburn J, Turner G, Daniel A, Brookwell R: The diagnosis and frequency of X-linked conditions in a cohort of moderately retarded males with affected brothers. Am J Med Genet 1983; 14: $713-724$

12 Mandel JL, Chelly J: Monogenic X-linked mental retardation: is it as frequent as currently estimated? The paradox of the ARX (Aristaless X) mutations. Eur J Hum Genet 2004; 12: 689-693.

13 Poirier K, Lacombe D, Gilbert-Dussardier B et al: Screening of ARX in mental retardation families: consequences for the strategy of molecular diagnosis. Neurogenetics 2005; 6: 1-8.
14 Knight SJ, Regan R, Nicod A et al: Subtle chromosomal rearrangements in children with unexplained mental retardation. Lancet 1999; 354: 1676-1681.

15 Flint J, Wilkie AO, Buckle VJ, Winter RM, Holland AJ, McDermid HE: The detection of subtelomeric chromosomal rearrangements in idiopathic mental retardation. Nat Genet 1995; 9: 132-140.

16 Rooms L, Reyniers E, Kooy RF: Subtelomeric rearrangements in the mentally retarded: a comparison of detection methods. Hum Mutat 2005; 25: 513-524.

17 De Vries BB, Winter R, Schinzel A, van Ravenswaaij-Arts C: Telomeres: a diagnosis at the end of the chromosomes. $J$ Med Genet 2003; 40: 385-398.

18 de Vries BB, White SM, Knight SJ et al: Clinical studies on submicroscopic subtelomeric rearrangements: a checklist. J Med Genet 2001; 38: 145-150.

19 Rodriguez-Revenga L, Badenas C, Sanchez A et al: Cryptic chromosomal rearrangement screening in 30 patients with mental retardation and dysmorphic features. Clin Genet 2004; 65: 17-23.

20 Koolen DA, Nillesen WM, Versteeg MH et al: Screening for subtelomeric rearrangements in 210 patients with unexplained mental retardation using multiplex ligation dependent probe amplification (MLPA). J Med Genet 2004; 41: 892-899.

21 Bocian E, Helias-Rodzewicz Z, Suchenek K et al: Subtelomeric rearrangements: results from FISH studies in 84 families with idiopathic mental retardation. Med Sci Monit 2004; 10: CR143-151.

22 Van Esch H, Bauters M, Ignatius J et al: Duplication of the MECP2 region is a frequent cause of severe mental retardation and progressive neurological symptoms in males. Am J Hum Genet 2005; 77: 442-453.

23 Vissers LE, de Vries BB, Osoegawa K et al: Array-based comparative genomic hybridization for the genomewide detection of submicroscopic chromosomal abnormalities. Am J Hum Genet 2003; 73: $1261-1270$

24 Vissers LE, van Ravenswaaij CM, Admiraal R et al: Mutations in a new member of the chromodomain gene family cause CHARGE syndrome. Nat Genet 2004; 36: 955-957.

25 Bi W, Saifi GM, Shaw CJ et al: Mutations of RAI1, a PHDcontaining protein, in nondeletion patients with Smith-Magenis syndrome. Hum Genet 2004; 115: 515-524.

26 Morison IM, Ramsay JP, Spencer HG: A census of mammalian imprinting. Trends Genet 2005; 21: 457-465.

27 Nicholls RD: The impact of genomic imprinting for neurobehavioral and developmental disorders. J Clin Invest 2000; 105: 413-418.

28 Walter J, Paulsen M: Imprinting and disease. Semin Cell Dev Biol 2003; 14: $101-110$.

29 Petersen MB, Brondum-Nielsen K, Hansen LK, Wulff K: Clinical, cytogenetic, and molecular diagnosis of Angelman syndrome: estimated prevalence rate in a Danish county. Am J Med Genet 1995; 60: 261-262.

30 Steffenburg S, Gillberg CL, Steffenburg U, Kyllerman M: Autism in Angelman syndrome: a population-based study. Pediatr Neurol 1996; 14: 131-136.

31 Nicholls RD, Knepper JL: Genome organization, function, and imprinting in Prader-Willi and Angelman syndromes. Аnnu Rev Genomics Hum Genet 2001; 2: 153-175.

32 Inlow JK, Restifo LL: Molecular and comparative genetics of mental retardation. Genetics 2004; 166: 835-881.

33 Lehrke R: Theory of X-linkage of major intellectual traits. Am J Ment Defic 1972; 76: 611-619.

34 Turner G: Intelligence and the X chromosome. Lancet 1996; 347: $1814-1815$.

35 Turner G, Partington MW: Genes for intelligence on the X chromosome. J Med Genet 1991; 28: 429.

36 Skuse DH: X-linked genes and mental functioning. Hum Mol Genet 2005; 14 (Spec No. 1): R27-R32.

37 Zechner U, Wilda M, Kehrer-Sawatzki H, Vogel W, Fundele R, Hameister H: A high density of X-linked genes for general 
cognitive ability: a run-away process shaping human evolution? Trends Genet 2001; 17: 697-701.

38 Francis F, Meyer G, Fallet C et al: Human disorders of cortical development - from past to present. Eur J Neurosci 2006; 23, in press.

39 Bahi N, Friocourt G, Carrie A et al: IL1 receptor accessory protein like, a protein involved in X-linked mental retardation, interacts with Neuronal Calcium Sensor-1 and regulates exocytosis. Hum Mol Genet 2003; 12: 1415-1425.

40 Bagni C, Greenough WT: From mRNP trafficking to spine dysmorphogenesis: the roots of fragile X syndrome. Nat Rev Neurosci 2005; 6: 376-387.

41 Koekkoek SK, Yamaguchi K, Milojkovic BA et al: Deletion of FMR1 in Purkinje cells enhances parallel fiber LTD, enlarges spines, and attenuates cerebellar eyelid conditioning in fragile X syndrome. Neuron 2005; 47: 339-352.

42 Schenck A, Bardoni B, Langmann C, Harden N, Mandel JL, Giangrande A: CYFIP/Sra-1 controls neuronal connectivity in Drosophila and links the Rac1 GTPase pathway to the fragile X protein. Neuron 2003; 38: 887-898.

43 Billuart P, Chelly J: From fragile X mental retardation protein to Rac1 GTPase: new insights from Fly CYFIP. Neuron 2003; 38: $843-845$.

44 Meng J, Meng Y, Hanna A, Janus C, Jia Z: Abnormal long-lasting synaptic plasticity and cognition in mice lacking the mental retardation gene Pak3. J Neurosci 2005; 25: 6641-6650.

45 Boda B, Alberi S, Nikonenko I et al: The mental retardation protein PAK3 contributes to synapse formation and plasticity in hippocampus. J Neurosci 2004; 24: 10816-10825.

46 Govek EE, Newey SE, Akerman CJ, Cross JR, Van der Veken L, Van Aelst L: The X-linked mental retardation protein oligophrenin-1 is required for dendritic spine morphogenesis. Nat Neurosci 2004; 7: $364-372$.

47 Ramakers GJ: Rho proteins, mental retardation and the cellular basis of cognition. Trends Neurosci 2002; 25: 191-199.

48 Jamain S, Quach H, Betancur C et al: Mutations of the X-linked genes encoding neuroligins NLGN3 and NLGN4 are associated with autism. Nat Genet 2003; 34: 27-29.

49 Laumonnier F, Bonnet-Brilhault F, Gomot $\mathrm{M}$ et al: X-linked mental retardation and autism are associated with a mutation in the NLGN4 gene, a member of the neuroligin family. Am J Hum Genet 2004; 74: 552-557.

50 Tarpey P, Parnau J, Blow $M$ et al: Mutations in the DLG3 gene cause nonsyndromic X-linked mental retardation. Am J Hum Genet 2004; 75: 318-324.

51 Carrie A, Jun L, Bienvenu T et al: A new member of the IL-1 receptor family highly expressed in hippocampus and involved in X-linked mental retardation. Nat Genet 1999; 23: 25-31.

52 D'Adamo P, Menegon A, Lo Nigro C et al: Mutations in GDI1 are responsible for X-linked non-specific mental retardation. Nat Genet 1998; 19: 134-139.

53 Bienvenu T, des Portes V, Saint Martin A et al: Non-specific Xlinked semidominant mental retardation by mutations in a Rab GDP-dissociation inhibitor. Hum Mol Genet 1998; 7: 1311-1315.

54 Dean C, Scholl FG, Choih J et al: Neurexin mediates the assembly of presynaptic terminals. Nat Neurosci 2003; 6: 708-716.

55 Scheiffele P, Fan J, Choih J, Fetter R, Serafini T: Neuroligin expressed in nonneuronal cells triggers presynaptic development in contacting axons. Cell 2000; 101: 657-669.

56 Geppert M, Goda Y, Stevens CF, Sudhof TC: The small GTPbinding protein Rab3A regulates a late step in synaptic vesicle fusion. Nature 1997; 387: 810-814.

57 Ishizaki H, Miyoshi J, Kamiya H et al: Role of rab GDP dissociation inhibitor alpha in regulating plasticity of hippocampal neurotransmission. Proc Natl Acad Sci USA 2000; 97: 11587-11592.

58 D'Adamo P, Welzl H, Papadimitriou S et al: Deletion of the mental retardation gene Gdi1 impairs associative memory and alters social behavior in mice. Hum Mol Genet 2002; 11: 2567-2580.

59 Kandel ER: The molecular biology of memory storage: a dialogue between genes and synapses. Science 2001; 294: 1030-1038.
60 Costa RM, Federov NB, Kogan JH et al: Mechanism for the learning deficits in a mouse model of neurofibromatosis type 1. Nature 2002; 415: 526-530.

61 Costa RM, Yang T, Huynh DP et al: Learning deficits, but normal development and tumor predisposition, in mice lacking exon 23a of Nf1. Nat Genet 2001; 27: 399-405.

62 Trivier E, De Cesare D, Jacquot S et al: Mutations in the kinase Rsk-2 associated with Coffin-Lowry syndrome. Nature 1996; 384: $567-570$.

63 De Cesare D, Jacquot S, Hanauer A, Sassone-Corsi P: Rsk-2 activity is necessary for epidermal growth factor-induced phosphorylation of CREB protein and transcription of c-fos gene. Proc Natl Acad Sci USA 1998; 95: 12202-12207.

64 Harum KH, Alemi L, Johnston MV: Cognitive impairment in Coffin-Lowry syndrome correlates with reduced RSK2 activation. Neurology 2001; 56: 207-214.

65 Petrij F, Giles RH, Dauwerse HG et al: Rubinstein-Taybi syndrome caused by mutations in the transcriptional co-activator CBP. Nature 1995; 376: 348-351.

66 Swank MW, Sweatt JD: Increased histone acetyltransferase and lysine acetyltransferase activity and biphasic activation of the ERK/RSK cascade in insular cortex during novel taste learning. J Neurosci 2001; 21: 3383-3391.

67 Amir RE, Van den Veyver IB, Schultz $\mathrm{R}$ et al: Influence of mutation type and $X$ chromosome inactivation on Rett syndrome phenotypes. Ann Neurol 2000; 47: 670-679.

68 Bienvenu T, Carrie A, de Roux N et al: MECP2 mutations account for most cases of typical forms of Rett syndrome. Hum Mol Genet 2000; 9: 1377-1384.

69 Meloni I, Bruttini M, Longo I et al: A mutation in the rett syndrome gene, MECP2, causes X-linked mental retardation and progressive spasticity in males. Am J Hum Genet 2000; 67: 982-985.

70 Couvert P, Bienvenu T, Aquaviva C et al: MECP2 is highly mutated in X-linked mental retardation. Hum Mol Genet 2001; 10: 941-946.

71 Tao J, Van Esch H, Hagedorn-Greiwe M et al: Mutations in the Xlinked cyclin-dependent kinase-like 5 (CDKL5/STK9) gene are associated with severe neurodevelopmental retardation. Am J Hum Genet 2004; 75: 1149-1154.

72 Weaving LS, Christodoulou J, Williamson SL et al: Mutations of CDKL5 cause a severe neurodevelopmental disorder with infantile spasms and mental retardation. Am J Hum Genet 2004; 75 : $1079-1093$.

73 Mari F, Azimonti S, Bertani I et al: CDKL5 belongs to the same molecular pathway of $\mathrm{MeCP} 2$ and it is responsible for the earlyonset seizure variant of Rett syndrome. Hum Mol Genet 2005; 14: $1935-1946$.

74 Kriaucionis S, Bird A: DNA methylation and Rett syndrome. Hum Mol Genet 2003; 12 (Spec No. 2): R221-R227.

75 Caballero IM, Hendrich B: MeCP2 in neurons: closing in on the causes of Rett syndrome. Hum Mol Genet 2005; 14 (Spec No. 1): R19-R26.

76 Nuber UA, Kriaucionis S, Roloff TC et al: Up-regulation of glucocorticoid-regulated genes in a mouse model of Rett syndrome. Hum Mol Genet 2005; 14: 2247-2256.

77 Chen RZ, Akbarian S, Tudor M, Jaenisch R: Deficiency of methyl-CpG binding protein-2 in CNS neurons results in a Rett-like phenotype in mice. Nat Genet 2001; 27: $327-331$.

78 Guy J, Hendrich B, Holmes M, Martin JE, Bird A: A mouse Mecp2null mutation causes neurological symptoms that mimic Rett syndrome. Nat Genet 2001; 27: 322-326.

79 Kishi N, Macklis JD: MECP2 is progressively expressed in postmigratory neurons and is involved in neuronal maturation rather than cell fate decisions. Mol Cell Neurosci 2004; 27: $306-321$.

80 Matarazzo V, Cohen D, Palmer AM et al: The transcriptional repressor Mecp2 regulates terminal neuronal differentiation. Mol Cell Neurosci 2004; 27: 44-58. 
81 Atkins CM, Selcher JC, Petraitis JJ, Trzaskos JM, Sweatt JD: The MAPK cascade is required for mammalian associative learning. Nat Neurosci 1998; 1: 602-609.

82 Butler FM, Miller SP, Lee KH, Pierce T: Teaching mathematics to students with mild-to-moderate mental retardation: a review of the literature. Ment Retard 2001; 39: 20-31.

83 Bat-haee MA: A longitudinal study of active treatment of adaptive skills of individuals with profound mental retardation. Psychol Rep 2001; 89: 345-354.

84 Gruters A, Jenner A, Krude H: Long-term consequences of congenital hypothyroidism in the era of screening programmes. Best Pract Res Clin Endocrinol Metab 2002; 16: 369-382.

85 Dashman T, Sansaricq C: Nutrition in the management of inborn errors of metabolism. Clin Lab Med 1993; 13: 407-432.

86 Levy BD, Serhan CN: Exploring new approaches to the treatment of asthma: potential roles for lipoxins and aspirin-triggered lipid mediators. Drugs Today (Barc) 2003; 39: 373-384.
87 Schulze A, Hess T, Wevers R et al: Creatine deficiency syndrome caused by guanidinoacetate methyltransferase deficiency: diagnostic tools for a new inborn error of metabolism. J Pediatr 1997; 131: $626-631$.

88 Schulze A, Ebinger F, Rating D, Mayatepek E: Improving treatment of guanidinoacetate methyltransferase deficiency: reduction of guanidinoacetic acid in body fluids by arginine restriction and ornithine supplementation. Mol Genet Metab 2001; 74: 413-419.

89 Alarcon JM, Malleret G, Touzani K et al: Chromatin acetylation, memory, and LTP are impaired in CBP+/- mice: a model for the cognitive deficit in Rubinstein-Taybi syndrome and its amelioration. Neuron 2004; 42: 947-959.

90 McBride SM, Choi $\mathrm{CH}$, Wang Y et al: Pharmacological rescue of synaptic plasticity, courtship behavior, and mushroom body defects in a Drosophila model of fragile X syndrome. Neuron 2005; 45: 753-764. 